\title{
IMMUNOLOGY OF CERVICAL CANCER
}

\author{
Joaquín Manzo-Merino ${ }^{1,2}$, Susana del-Toro-Arreola ${ }^{3}$, Leticia Rocha-Zavaleta ${ }^{4}$, \\ Óscar Peralta-Zaragoza ${ }^{6}$, Roberto JimÉnez-Lima ${ }^{5}$, And Vicente Madrid-Marina ${ }^{6 *}$ \\ ${ }^{1}$ Department of Basic Research, Instituto Nacional de Cancerología, Mexico City; ${ }^{2}$ Consejo Nacional de Ciencia \\ y Tecnología (CONACyT)-Instituto Nacional de Cancerología, Mexico City; ${ }^{3}$ Department of Physiology, University \\ Center for Health Sciences, Universidad de Guadalajara, Guadalajara, Jal.; ${ }^{4}$ Department of Molecular Biology \\ and Biotechnology, Instituto de Investigaciones Biomédicas, Universidad Nacional Autónoma de México (UNAM), \\ Mexico City; ${ }^{5}$ Department of Clinical Research, Instituto Nacional de Cancerología, Mexico City; ${ }^{6}$ Infectious Diseases \\ Research Center, Instituto Nacional de Salud Pública, Cuernavaca, Mor., Mexico
}

\begin{abstract}
Optimal function of the immune system allows the recognition and elimination of infected and tumor cells. However, these cells can develop mechanisms to evade the cellular immune response. In human papillomavirus (HPV) infection, dysregulation of major histocompatibility complex Class I molecules and other components of the innate immune system promote the survival of infected cells by allowing the infection to persist which, in turn, favors the development of cancer. Further, tumor cells possess inherent mechanisms designed to block the recognition and activation of cytotoxic lymphocytes: particularly, HPV proteins such as E1 and E2 and oncoproteins E5, E6, and E7 that inhibit immune mechanisms and/or stimulate the expression of immunosuppressive cytokines. These mechanisms include a decrease in receptor activation and costimulating molecules on the surface of immune cells, as well as the constitutive expression of molecules that inhibit their function, which allow HPV persistence and tumor progression. Immunotherapy-based therapeutic options are positioned as excellent candidates for the treatment of cervical cancer. (REV INVEST CLIN. 2020;72(4):188-97)
\end{abstract}

Key words: Cervical cancer. Human papillomavirus. Cytotoxic T lymphocyte-associated protein 4. Programmed death protein-1. Programmed death ligand-1. Activation.

\section{INTRODUCTION}

Human papillomavirus (HPV) infection represents one of the most prevalent sexually transmitted infections, particularly in the sexually active population, but only $10 \%$ of cases will develop a persistent infection ${ }^{1}$. HPV infection persistence is recognized as a requirement for the development of invasive cancer ${ }^{2}$. This implies that the majority of infected individuals have effective defense mechanisms to eliminate the initial HPV infection.

High-risk HPV E6 and E7 oncoproteins are known to contribute to cervical carcinogenesis by inactivating tumor cell suppression proteins, mainly p53 and retinoblastoma protein ( $\mathrm{pRb}$ ), therefore, prolonging the cell cycle with apoptosis suppression and predisposing cells to neoplastic transformation. In addition, viral
*Corresponding author:

Vicente Madrid-Marina

E-mail:vmarina@insp.mx
Received for publication: 20-02-2020

Approved for publication: 30-03-2020

DOI: $10.24875 / R I C .20000057$

0034-8376 / (c) 2020 Revista de Investigación Clínica. Published by Permanyer. This is an open access article under the CC BY-NC-ND license (http://creativecommons.org/licenses/by-nc-nd/4.0/). 
Figure 1. Human papillomavirus (HPV) reaches the epithelial basal layer through microabrasions. Once the infection is established, the first line of defense against HPV is the innate immune response, where the recruitment of Langerhans cells, dendritic cells, NK cells with their varied repertoire of activation receptors, and natural killer T cells (a type of T lymphocyte aimed at innate immunity) takes place, with rapid production of antiviral cytokines such as interferon- $\gamma$. Subsequently, a highly specific response to eliminate the infection will include CD4+ T lymphocytes polarized to a T-helper lymphocyte 1 phenotype and induction of a cytotoxic response mediated by cytolytic CD8+ T lymphocytes.

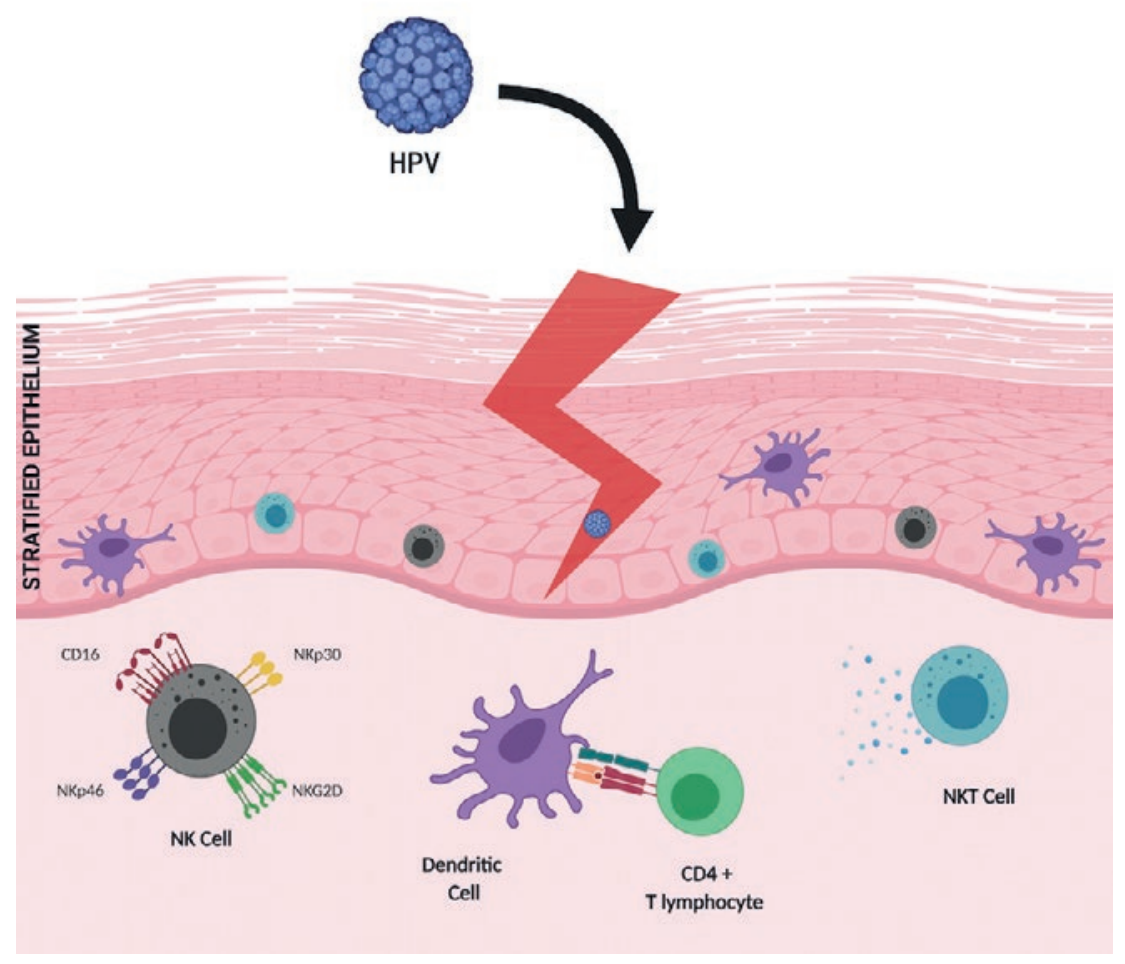

oncoproteins have been reported to be able to interfere with components of the immune response ${ }^{1}$. This review describes the different mechanisms used by the HPV-transformed cells aimed to evade immune recognition and elimination.

A review of the literature was performed employing the PICO acronym to detect articles encompassing immune response, HPV, and cervical cancer (CC). Key words used in the PubMed database included "CC," cancer," "HPV," "immune evasion," "T cell activation," "CD4," "T-cell receptor (TCR)," "HPV E6," "HPV E7," "HPV infection," "Cytotoxic T Lymphocyte-Associated Protein 4 (CTLA-4)," "programmed death protein-1 (PD-1)," "programmed death ligand 1 (PD-L1)," "therapeutic target," and "immunotherapy." Manuscripts focusing in Mexican population were detected and others from different regions were also included, articles published in English language over the past 15 years were included to ensure scientific validity.

Articles were revised by all authors, and the information processed according to the GRADE system. Evidence was classified and then recommendations were posed according to the strength of the evidence.

\section{CELLULAR IMMUNE RESPONSE AGAINST HPV-ASSOCIATED CERVICAL CANCER}

HPV reaches the epithelial basal layer through microlesions, where physical barriers play an important role in preventing HPV infection in basal cells (Fig. 1). The presence of mucoproteins, an acidic $\mathrm{pH}$, as well as certain human defensins such as HD5 prevents the virus from entering the keratinocyte ${ }^{3}$. However, oftentimes, HPV can evade these mechanisms and 
infect its target cell. Once infection is established, the first line of defense against HPV is mediated by the innate immune response. To initiate an effective defense against infected cells, it is important to trigger a rapid inflammatory response $\mathrm{A}^{4}$. In the early response, cell recruitment takes place and includes dendritic cells (DC), Langerhans cells (LC), natural killer (NK) cells, and NK T cells (NKT) at the site of infection. All these cells are also involved in promoting an immune response against infection, and most can foster a cytokine-mediated pro-inflammatory process. Among these, type I interferons (IFNs) are involved in the activation of adaptive immune response cells by regulating cytotoxic $T$ cell differentiation, DC maturation, and NK cell activation ${ }^{5}$. In patients with CC, the HPV E7 oncoprotein has been shown to inhibit the expression of genes induced by IFN regulatory factors. This blocks IFN-alpha activity, which prevents the release of inflammatory cytokines at the site of infection as well as DC maturation and consequently, inhibits the $T$ lymphocyte-mediated cytotoxic response $^{6}$. In addition, in response to the presence of HPV 16 virus-like particles in CC, plasmacytoid DCs have been observed to secrete several cytokines such as IFN-alpha, interleukin 6, or tumor necrosis factoralpha?.

Given that the HPV life cycle is strictly intraepithelial, the immune response of host cells, basal keratinocytes, is necessary to promote HPV elimination. Basal keratinocytes are considered immune system sentinels by acting as non-professional antigen-presenting cells (APCs) and by inducing the expression of Thelper lymphocyte 1 and Th2-type cytokines, as well as a CD8+ T lymphocyte-mediated cytotoxic response. In the female genital tract, keratinocytes express several Toll-like receptors (TLRs), which are capable of recognizing pathogen-associated molecular patterns. The presence of non-methylated viral DNA activates these receptors, triggering the innate and adaptive immune responses, which, in turn, promote cytokine production and create a pro-inflammatory environment with the ultimate goal of eliminating the infection ${ }^{4,8}$.

When removing infected cells through the cytotoxicity mechanism, major histocompatibility complex (MHC) Class I (MHC-I) molecules intervene and are recognized by NK cells and cytotoxic T lymphocytes. NK cells are able to recognize and eliminate
HPV-infected cells, and therefore, functional deficiencies in NK cells have been associated with increased HPV infections and a higher incidence of related cancer $^{9}$. Cells that exhibit normal expression of MHC-I molecules are protected from the activity of NK cells; however, HPV-infected cells show a decrease in MHCI expression induced by viral oncoproteins, which leads to their elimination by NK cells. In addition, once viral proteins are processed by the immunoproteasome/ endoplasmic reticulum, they form stable complexes with the MHC-I heavy chain and beta-2-microglobulin accessory protein, which migrate to the cell surface and induce a specific cytotoxic response by $C D 8+T$ cells and infected cell lysis ${ }^{10}$.

In some tumors, it is common to observe changes in MHC-I and II expression, and especially a decrease in the expression of MHC-I molecules. In fact, HPV6 E6 oncoprotein reduces $\mathrm{MHC}-\mathrm{I}$ protein levels by inhibiting the expression of MHC-I genes. Apparently, HPV16 E6 can modulate MHC-I expression, unlike HPV18, which is unable to do it, and thus promote the suppression of the adaptive immune response ${ }^{11}$. In addition, the HPV E5 oncoprotein also regulates the levels of MHC-I complexes by interfering with their positioning on the cell surface, thereby preventing the recognition of infected cells ${ }^{12}$.

In summary, HPV infection promotes a rapid and short-lasting inflammatory response, as well as the recruitment of cells involved in immunity. The presence of the virus induces a specific cytotoxic response mediated by MHC-I that leads to infected cell lysis. However, in some susceptible women, the virus has mechanisms to evade the immune response by decreasing MHC-I expression or blocking IFN activity, which generates an immunosuppressive microenvironment, in which immunosuppressive cytokines such as IL-10 and transforming growth factor beta (TGFbeta) participate ${ }^{13}$.

HPV manages to evade the immune response by preventing and minimizing its exposure to the immune system. HPV replication and release do not cause cell death, given that differentiated keratinocytes are already programmed to die; furthermore, HPV takes advantage of the keratinocyte differentiation program to complete its viral cycle in the superficial layers where the assembly of new virions takes place and is released by the action of the viral protein E4 during 
the natural desquamation process ${ }^{14}$, so a danger signal activating the immune system is not generated. On the other hand, HPV minimizes the expression of capsid proteins and delays their expression in the differentiated epithelium to avoid or delay their detection by LCs, which allows the establishment of persistent or latent infection in host cells. In patients with CC, dead cells released during normal turnover of the cervical epithelium are phagocytosed by LCs, which release immunosuppressive cytokines such as TGFbeta, IL-10, and IL-13. Furthermore, through the effect of these cytokines, HPV infection prevents the activation and maturation of DCs and inhibits the triggering of the $\mathrm{T}$ lymphocyte positive cytotoxic response ${ }^{15-18}$.

Another mechanism through which recognition is prevented, in infected or transformed cells, is the absence of costimulatory molecules and $T$ lymphocyte activation receptors. Costimulatory molecules identify and eliminate transformed cells. Several studies have established the ability of HPV to regulate the type and amount of these molecules in HPV-positive cells. Tummers et al. (2014) determined the importance of CD40 activation during inflammatory and antitumor responses, reporting that after $48 \mathrm{~h}$ of ligation, a phenotype that is necessary for the development and maintenance of the adaptive immune response is promoted, but weakened by the effect of $\mathrm{HPV}^{19}$. CD40 expression is promoted by the transcriptional factor of the AT-Hook AKNA type ${ }^{20}$, which is a regulation target for HPV. As a result of this dysregulation, CD40 and IL-8 are decreased ${ }^{21}$. In addition, HPV is capable of modifying cytokine levels as a mechanism of evading the immune system, thus inhibiting the pro-inflammatory response in keratinocytes. High-risk HPV E6 and E7 oncoproteins inhibit TLR9 expression, which limits their ability to induce the expression of pro-inflammatory genes that are essential for an immune response against viral infection $^{22}$.

NK cells are known to be important effectors of early immune surveillance of tumors. The activity of these cells is finely regulated by the balance between inhibition receptors, whose main ligands are MHC-I molecules, and activation receptors, which partially recognize ligands induced after cellular stress ${ }^{23}$. In the particular case of CC, the loss of MHC-I caused by HPV oncoproteins would leave the tumor cell susceptible to the cytotoxic effect of NK cells. However, NK cells in these patients have been observed to often be dysfunctional and are, therefore, unable to mount an effective cytotoxic response against the tumor. This dysfunction can be explained by defects in the expression of important activation receptors such as NKp3O and NKp46, which have been observed to be decreased in the peripheral NK cells of patients with CC and, in addition, this decrease is consistent with defects in their cytotoxic activity ${ }^{24}$. These findings suggest that defects in activation receptors may support CC progression.

The proportion of CD4+ and CD8+ T cells is related to the severity of the lesions in the cervical mucosa. Patients with cervical intraepithelial neoplasia (CIN) in regression or low-risk HPV-induced genital warts have a higher proportion of CD4+ than CD8+ T cells, while in patients with advanced lesions and invasive $\mathrm{CC}$, the proportion of $\mathrm{CD} 8+$ is higher ${ }^{25,26}$. Despite the increase in the number of cells responsible for the elimination of tumor cells, they are anergic and nonfunctional ${ }^{27}$. Table 1 summarizes a variety of abnormalities through which CC evades cellular immunity, promoting tumor growth and dissemination.

\section{IMMUNE CHECKPOINTS: CTLA-4, PD-1/PD-L1, AS IMMUNE MOLECULAR TARGETS IN CERVICAL CANCER}

The immune response against virus-infected cells and against tumor cells is regulated by the interaction between APCs and T lymphocytes (Fig. 2A). APCs express on their membrane a series of costimulatory and corepressor molecules, which bind to the receptors present on the antigen presentation-activated T-cell membrane. These molecules are known as immune checkpoints and, as a whole, they are responsible for maintaining homeostasis after an immune response ${ }^{28}$.

\section{CTLA-4 AND CERVICAL CANCER}

The activation of checkpoints in T lymphocytes is a sequential phenomenon, and their function is not redundant ${ }^{29}$, so after antigen recognition by the TCR, binding of the CD28 receptor to its ligands (CD80 and CD86) occurs in APCs. This induces positive signals 
Table 1. Summary of immune abnormalities in patients with cervical cancer

\begin{tabular}{|c|c|c|}
\hline Alteration & Consequences & References \\
\hline \multirow[t]{2}{*}{$\begin{array}{l}\text { Loss of MHC-I molecule expression } \\
\text { in cervical cancer }\end{array}$} & $\begin{array}{l}\text { Defects in the response by cytotoxic CD8+ } \\
\text { T lymphocytes }\end{array}$ & 11,41 \\
\hline & $\begin{array}{l}\text { Resistance to cytotoxic T lymphocyte- } \\
\text { induced lytic activity }\end{array}$ & \\
\hline $\begin{array}{l}\text { Altered cytotoxic CD8+ T lymphocytes } \\
\text { in cervical neoplasm }\end{array}$ & $\begin{array}{l}\text { CD4/CD8 ratio is altered in favor of CD8 } \mathrm{T} \\
\text { lymphocytes Decrease in IFN- } \gamma \text { and IL-5 }\end{array}$ & 25 \\
\hline $\begin{array}{l}\text { Decreased TCR/CD3 complex zee chain } \\
\text { in T lymphocytes }\end{array}$ & $\begin{array}{l}\text { Defects in the signals generated through } \\
\text { TCR/CD3, which affect the proliferation } \\
\text { and production of cytokines }\end{array}$ & 27 \\
\hline Decreased E-cadherin in cervical cancer cells & $\begin{array}{l}\text { Defects in the retention of Langerhans cells } \\
\text { in the epidermis and subsequent immune } \\
\text { masking }\end{array}$ & 42 \\
\hline $\begin{array}{l}\text { Death by apoptosis of CD4+ and CD8+ } \\
\text { effector T lymphocytes }\end{array}$ & $\begin{array}{l}\text { Apoptosis induction and T lymphocyte } \\
\text { proliferation inhibition through the } \\
\text { production of soluble factors }\end{array}$ & 43,44 \\
\hline \multirow[t]{2}{*}{$\begin{array}{l}\text { Increase of immunosuppressive cytokines } \\
\text { in the cervix }\end{array}$} & $\begin{array}{l}\text { Suppression of specific immune responses in } \\
\text { the tumor microenvironment by IL-10 and } \\
\text { TGF-beta }\end{array}$ & 17,18 \\
\hline & $\begin{array}{l}\text { Maintenance of viral persistence and } \\
\text { transformed cells }\end{array}$ & \\
\hline \multirow[t]{2}{*}{$\begin{array}{l}\text { Increased Treg lymphocyte recruitment } \\
\text { in the cervix }\end{array}$} & $\begin{array}{l}\text { Destruction of tumor immune surveillance } \\
\text { by counterattacking tumor infiltrating } T \\
\text { lymphocytes (TIL) }\end{array}$ & 45,46 \\
\hline & $\begin{array}{l}\text { Cytotoxic CD8+ T lymphocyte function } \\
\text { inhibition }\end{array}$ & \\
\hline $\begin{array}{l}\text { Absence of functional CD40 on the surface } \\
\text { of tumor cells }\end{array}$ & $\begin{array}{l}\text { Absence of CD40 in APC does not allow } \mathrm{T} \\
\text { lymphocyte activation, with subsequent } \\
\text { decrease in pro-inflammatory cytokines }\end{array}$ & 21 \\
\hline \multirow{2}{*}{$\begin{array}{l}\text { Loss of CD28 and perforin acquisition in } \\
\text { the population of circulating CD } 4+T \text { cells } \\
\text { in CC }\end{array}$} & $\begin{array}{l}\text { The role of CD4+ CD28null T cells in CC } \\
\text { is not clear. }\end{array}$ & 47 \\
\hline & They might act on tumor growth & \\
\hline $\begin{array}{l}\text { CD28 and CTLA-4 dysregulated expression } \\
\text { in peripheral T lymphocytes of patients } \\
\text { with CC }\end{array}$ & $\begin{array}{l}\text { Altered } T \text { lymphocyte function that leads } \\
\text { to systemic immunosuppression }\end{array}$ & 32 \\
\hline $\begin{array}{l}\text { Increased expression of PD-L1 in tissues } \\
\text { of patients with CC and of PD- } 1 \text { in stromal } \\
\text { mononuclear cells (identified as TIL) }\end{array}$ & $\begin{array}{l}\text { Overexpression of the PD-1/PD-L1 axis, } \\
\text { one of the main pathways of immune } \\
\text { control in T lymphocytes, leads to a } \\
\text { potent inhibition of antitumor immune } \\
\text { responses }\end{array}$ & 48,49 \\
\hline
\end{tabular}

HPV: human papillomavirus; MHC: major histocompatibility complex; CTLA-4: cytotoxic T Iymphocyte-associated protein 4; PD-1: programmed death protein-1; PD-L1: programmed death ligand 1; TCR: T lymphocyte receptor.

for T lymphocyte activation, but also favors the translocation of the CTLA-4 inhibitor receptor to the lymphocyte membrane. CTLA-4 is homologous to the costimulatory protein $\mathrm{CD} 28$ which it competes with, but its affinity is approximately 20 times higher for the $\mathrm{CD} 80 / \mathrm{CD} 86$ ligands $^{30}$. By binding to its ligands, CTLA-4 activation induces its association with phosphatases that inactivate molecules such as the TCR CD3-zeta chain ${ }^{28}$ and $\mathrm{Akt}^{31}$, thus inhibiting the signaling cascades that promote cytotoxic $T$ lymphocyte activity.

The clear association between cellular immune activity and the natural response to HPV infection and its 
Figure 2. Elimination of infected cells and tumor cells. A. Induction of a cytotoxic response mediated by cytolytic CD8+ T cells against infected cells. B. Under certain circumstances, the use of anti-cytotoxic T lymphocyte-associated protein 4 antibodies might promote the expression of programmed death protein-1 receptors, a strategy that could be exploited as a therapeutic target in the treatment of cervical cancer.
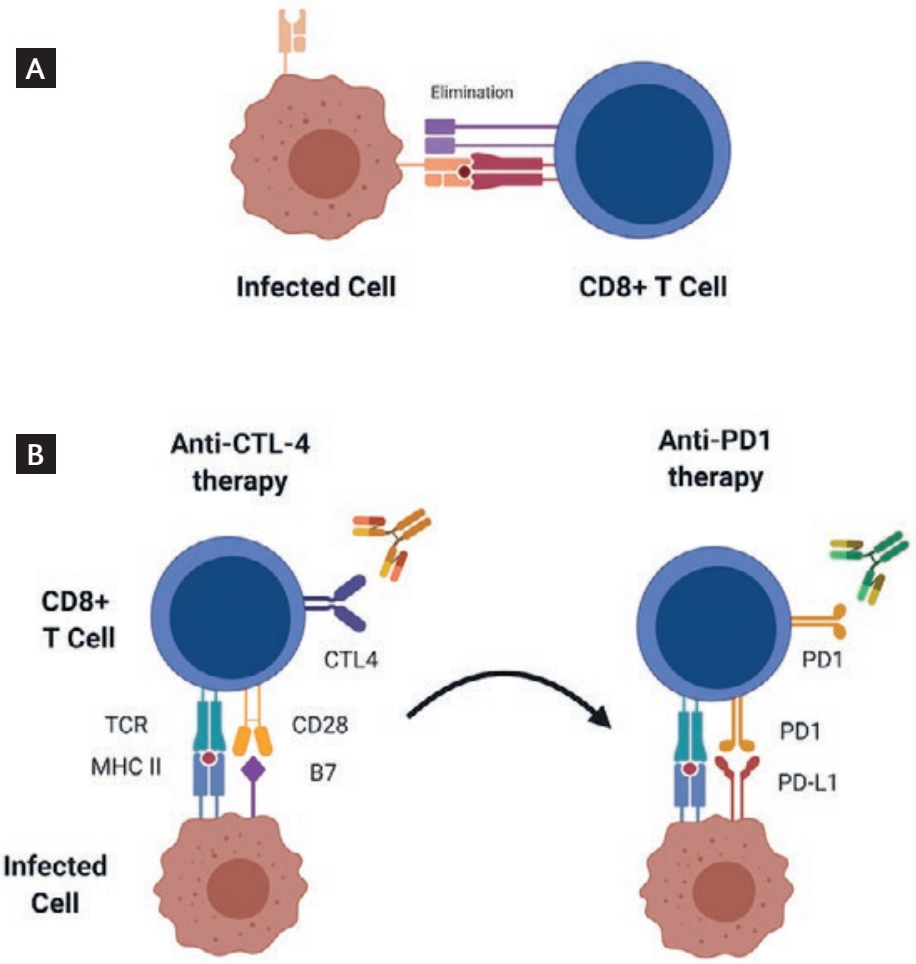

associated lesions suggest that during the development of CC, there are cell response failures that limit the recognition and elimination of tumor cells. An analysis by Kosmaczewska et al. showed that an abnormally high proportion of circulating CD4 $+\mathrm{T}$ cells from patients with CC express CTLA-4, while a significant decrease in CD28 expression is observed in $\mathrm{CD} 8+\mathrm{T}$ cells $^{32}$. These observations appear to indicate that the T-cell-mediated response against tumor cells could be inhibited by the presence of CTLA- 4 and suggest that patients with $C C$ could benefit from immunotherapy directed at blocking CTLA-4 (Fig. 2B).

As a result, a Phase I-II clinical trial was conducted to explore the possible anti-tumor effect of ipilimumab in patients with HPV-associated metastatic or recurrent $\mathrm{CC}^{33}$. Ipilimumab is a humanized monoclonal antibody that blocks the membrane CTLA- 4 molecule with high affinity and was approved by the FDA in 2010 for the management of different types of can$\mathrm{cer}^{34}$. The reported study is a multicenter protocol that recruited 42 patients with HPV-positive CC and resistant to cisplatin. The efficacy of ipilimumab as monotherapy was tested and the results showed that CTLA4 blockade, targeted therapy did not increase patient overall survival or the progression-free interval, and therefore, patients with CC were considered not to be benefited by this type of immunotherapy. However, an analysis of the activation status and the expression of markers in circulating lymphocytes showed that treatment with ipilimumab induced the expression of the inhibitory molecule PD- ${ }^{33}$, which opens a new perspective and the possibility of immunotherapy in CC, using antibodies targeting PD-1.

\section{PD-1/PD-L1 AND CERVICAL CANCER}

Another immune checkpoint that has drawn attention in recent years is undoubtedly the PD-1 molecule, initially described in the T-cell population; however, PD-1 is also known to be expressed in B cells, mainly 
NK and DC cells. Two PD-1 ligands, PD-L1 and PD-L2, both members of the B7 family, are known. PD-L1 can be induced by various cytokines, such as IFN-alpha, and its expression encompasses a wide variety of cells both hematopoietic (including APC, such as DC), and non-hematopoietic in nature (e.g., tumor cells and tumor-associated fibroblasts), while the expression of PD-L2, which is induced by IL-4 and IFN, is restricted to DCs, macrophages, mast cells, and some $B$ cells ${ }^{30}$.

The interaction between PD-L1 in APCs and its PD-1 counterpart in activated $T$ lymphocytes leads to the inhibition of the latter cells, which results in apoptosis induction or leads to a state of anergy, which inhibits the production of cytokines and cytolytic function ${ }^{35}$. In addition, PD-1 expression enhances the conversion of immature $C D 4+T$ cells into regulatory $T$ cells (Tregs), causing immune response attenuation. The PD-1/PD-L1 axis is known to represent a novel therapeutic target in different tumors; however, the clinical significance of PD-L1 expression in CC has not been fully elucidated. For example, PD-L1 overexpression has been reported in a variety of malignant tumors, causing cytotoxic CD8+ T cells present in the tumor microenvironment to shut down their lytic function, and thus, it becomes a protective mechanism against cell death.

At present, there are several studies that have reported the expression of PD-L1 in CC samples. For example, HPV16 E7 expression has been associated with PD-L1 expression in CC cells ${ }^{35}$. A recent study in patients with CC showed PD-L1 expression in 34\% of samples; when the samples were subcategorized, a larger number of positive samples were observed in squamous cell carcinoma (38\%), in comparison with adenosquamous carcinoma and endocervical adenocarcinoma ( $29 \%$ and $17 \%$, respectively). Notably, PDL1 was not found in normal cervical samples or in benign cervical lesions ${ }^{36,37}$. Another study showed PD-L1 positivity in $>5 \%$ of tumor cells and in $54 \%$ of squamous-cell carcinomas versus $14 \%$ for adenocarcinomas $(p<0.001)$. Interestingly, in that same study, positivity for PD-L1 was also found in tumor infiltrating immune cells, as well as in stromal immune cells, most of them identified as tumor-associated macrophages ${ }^{38}$. Finally, another study showed that PD-L1 expression is associated with efficient HPV infection and that it is also significantly overexpressed in both CC cells and surrounding inflammatory cells in comparison with other gynecological tumors ${ }^{39}$.

Overall, the discovery of this important negative regulatory pathway in the biology of $\mathrm{T}$ cells has opened new therapeutic options, such as immunotherapy with the use of antibodies targeted against PD-1 or PD-L1, designed to block the interaction between the receptor and its ligands, which has shown established clinical benefit in a variety of tumors, including CC; these are currently being investigated in Phase I/II clinical trials. Therefore, directing therapies against multiple immune pathways, in particular, with antagonists of the PD-1/PD-L1 pathway (Fig. 2B), might overcome tumor resistance to immune effector mechanisms, especially in advanced or recurrent tumors (Table 2).

\section{OTHER IMMUNE CHECKPOINTS AS POSSIBLE THERAPEUTIC TARGETS FOR CERVICAL CANCER}

As previously mentioned, NK cell-mediated cytotoxic activity is pivotal to the immune response against HPV-infected cells and CC cells. Since abnormalities in NK cell function have been observed during the development of CC, it is reasonable to consider that this type of cancer could be a candidate for treatment with new immunotherapies targeting molecules which inhibit NK lymphocyte function as, for example, some killer cell immunoglobulin-like receptors (KIRs) which are overexpressed in CC and that is currently under development ${ }^{40}$.

\section{CONSIDERATIONS}

According to our current knowledge on immune responses in CC and to the critical elements that are compromised during the development of HPV-associated tumors, CC is considered to be a good candidate for treatment with immunotherapeutic strategies. At present, there are three commercially available immunotherapeutic options that use antagonist monoclonal antibodies: (1) against CTLA-4, (2) against PD-1, and (3) against PD-L1. In the case of CC, CTLA4 expression has been reported in a high proportion of analyzed samples; however, this treatment's efficacy proved to be of little benefit to patients, but the 
Table 2. Immunotherapy (alone or combined) against cervical cancer: current clinical trials based on the use of antibodies targeting immune checkpoints or their ligands

\begin{tabular}{|c|c|c|c|c|c|c|}
\hline $\begin{array}{l}\text { Registry } \\
\text { number }\end{array}$ & Treatment & Type of antibody & Target & Phase & Type of tumor & Reference(s) \\
\hline NCT01711515 & Ipilimumab & $\begin{array}{l}\text { Human monoclonal } \\
\text { antibody (IgG1) }\end{array}$ & CTLA-4 & I & $\begin{array}{l}\text { Stage IB2-IIB or IIIB-IVA } \\
\text { cervical cancer }\end{array}$ & 50 \\
\hline $\begin{array}{l}\text { NCT02635360 } \\
\text { NCT02628067 }\end{array}$ & Pembrolizumab & $\begin{array}{l}\text { Humanized } \\
\text { monoclonal } \\
\text { antibody (lgG4) }\end{array}$ & PD-1 & ॥ & $\begin{array}{l}\text { Advanced cervical } \\
\text { cancer }\end{array}$ & 50,51 \\
\hline NCT03298893 & Nivolumab & $\begin{array}{l}\text { Human monoclonal } \\
\text { antibody (lgG4) }\end{array}$ & PD-1 & I & $\begin{array}{l}\text { Locally advanced } \\
\text { cervical cancer }\end{array}$ & 52,53 \\
\hline NCT02921269 & Atezolizumab & $\begin{array}{l}\text { Humanized } \\
\text { monoclonal } \\
\text { antibody (IgG1) }\end{array}$ & PD-L1 & ॥ & $\begin{array}{l}\text { Recurrent, persistent } \\
\text { or metastatic } \\
\text { cervical cancer }\end{array}$ & 52 \\
\hline
\end{tabular}

CTLA-4: cytotoxic T lymphocyte-associated protein 4; PD-1: programmed death protein-1; PD-L1: programmed death ligand 1.

use of CTLA-4-targeted therapy induced PD-1expression. This is relevant, because there are data indicating that not all patients with CC express PD- 1 , and thus would not be candidates for therapy targeting this molecule and/or its receptor.

Overall, this opens the possibility of establishing sequential treatment strategies using existing commercial antibodies. Furthermore, knowledge of the presence of other altered immune checkpoints in CC, such as KIRs, suggests that this type of tumor should be considered as a model to prospectively study the efficacy of therapies that are currently under development and that use this checkpoint as a target.

\section{CONCLUSIONS}

The immune response plays a preponderant role in the elimination of CC cells. Failures in critical points of the cellular immune response foster the development of tumors. Given the information described, CC is a candidate for immunotherapy treatment.

\section{Recommendations}

1. Altered CTLA-4 expression has been observed in CC. Therapy aimed at blocking CTLA-4 has not been successful; however, CTLA-4 blockade induced PD-1 expression, which suggests that a sequential treatment strategy might favor the response of these patients when treated with combined therapies, targeting both CTLA-4 and PD-1. Quality of evidence: (GRADE) moderate. Strength of recommendation: strong in favor of its use.

2. The degree of response with the use of immunotherapy will largely depend on PD- 1 and PDL- 1 targets' expression. Therefore, it is necessary to determine the degree of expression of these molecules to ensure therapeutic success. Quality of evidence: (GRADE) high. Strength of recommendation: strong in favor of its use.

3. It is advisable to include CC as a candidate for new therapies. KIRs provide a strong strategy in the treatment of cancer. Therefore, studies with antiKIR antibodies might prove to be a promising strategy for the treatment of CC. Quality of evidence: (GRADE) low. Strength of recommendation: weak in favor of its use.

4. The study of possible therapeutic combinations for CC represents an opportunity to provide new treatment regimens to decrease adverse effects and improve treatment responses. Quality of evidence: (GRADE) low. Strength of recommendation: weak in favor of its use.

5. It is necessary to delve into the molecular mechanisms involved in cellular immune response control in cervical tumors to detect possible novel therapeutic targets. Quality of evidence: (GRADE) high. 


\section{Strength of recommendation: strong in favor of its use.}

\section{The implementation of efficacious methods in the production and purification of immunotherapeutic agents will potentially provide tools for a rapid and successful implementation of immunotherapy. Quality of evidence: (GRADE) low. Strength of rec- ommendation: weak in favor of its use.}

\section{ACKNOWLEDGMENTS}

We are grateful to Fabiola Solórzano Ibarra and Diego O. Reyes Hernández for their support in the design and editing of the figures.

\section{REFERENCES}

1. Christensen ND. HPV disease transmission protection and control. Microb Cell. 2016;3:476-90.

2. Walboomers JM, Jacobs MV, Manos MM, Bosch FX, Kummer JA, Shah $\mathrm{KV}$, et al. Human papillomavirus is a necessary cause of invasive cervical cancer worldwide. J Pathol. 1999;189:12-9.

3. Buck CB, Day PM, Thompson CD, Lubkowski J, Lu W, Lowy DR, et al. Human alpha-defensins block papillomavirus infection. Proc Natl Acad Sci U S A. 2006;103:1516-21.

4. Smola S, Trimble C, Stern PL. Human papillomavirus-driven immune deviation: challenge and novel opportunity for immunotherapy. Ther Adv Vaccines. 2017;5:69-82.

5. Senba M, Mori N. Mechanisms of virus immune evasion lead to development from chronic inflammation to cancer formation associated with human papillomavirus infection. Oncol Rev. 2012;6:e17

6. Patel S, Chiplunkar S. Host immune responses to cervical cancer. Curr Opin Obstet Gynecol. 2009;21:54-9

7. Westrich JA, Warren CJ, Pyeon D. Evasion of host immune defenses by human papillomavirus. Virus Res. 2017;231:21-33.

8. Amador-Molina A, Hernández-Valencia JF, Lamoyi E, ContrerasParedes $A$, Lizano $M$. Role of innate immunity against human papillomavirus (HPV) infections and effect of adjuvants in promoting specific immune response. Viruses. 2013;5:2624-42.

9. Orange JS. Natural killer cell deficiency. J Allergy Clin Immunol. 2013;132:515-25

10. Hoos A, D'Incan C, Gissmann L, Altmann A, Momburg F, Nindl I, et al. Human papillomavirus Type 16 (HPV 16) E7 and major histocompatibility complex (MHC) Class I and II expression in human keratinocytes in culture. Arch Virol. 1996;141:449-58.

11. Kim DH, Kim EM, Lee $E H$, Ji KY, Yi J, Park $M$, et al. Human papillomavirus $16 \mathrm{E} 6$ suppresses major histocompatibility complex Class I by upregulating lymphotoxin expression in human cervical cancer cells. Biochem Biophys Res Commun. 2011; 409:792-8

12. DiMaio D, Petti LM. The E5 proteins. Virology. 2013;445:99-114.

13. Peralta-Zaragoza O, Bermúdez-Morales V, Gutiérrez-Xicotencat L, Alcocer-González J, Recillas-Targa F, Madrid-Marina V. E6 and E7 oncoproteins from human papillomavirus Type 16 induce activation of human transforming growth factor betal promoter throughout Sp1 recognition sequence. Viral Immunol. 2006;19:468-80

14. Doorbar J, Egawa N, Griffin H, Kranjec C, Murakami I. Human papillomavirus molecular biology and disease association. Rev Med Virol. 2015;25 Suppl 1:2-3.

15. Stanley MA. Epithelial cell responses to infection with human papillomavirus. Clin Microbiol Rev. 2012;25:215-22.

16. Tindle RW. Immune evasion in human papillomavirus-associated cervical cancer. Nat Rev Cancer. 2002;2:59-65.
17. Alcocer-González JM, Berumen J, Taméz-Guerra R, BermúdezMorales V, Peralta-Zaragoza O, Hernández-Pando R, et al. In vivo expression of immunosuppressive cytokines in human papillomavirus-transformed cervical cancer cells. Viral Immunol. 2006;19:481-91.

18. Torres-Poveda K, Bahena-Román M, Madrid-González C, Burguete-García Al, Bermúdez-Morales VH, Peralta-Zaragoza O, et al. Role of IL-10 and TGF- $\beta 1$ in local immunosuppression in HPV-associated cervical neoplasia. World J Clin Oncol. 2014;5:753-63.

19. Tummers B, Goedemans R, Jha V, Meyers C, Melief CJM, van der Burg $\mathrm{SH}$, et al. CD40-mediated amplification of local immunity by epithelial cells is impaired by HPV. J Invest Dermatol. 2014;134:2918-27.

20. Siddiqa A, Sims-Mourtada JC, Guzman-Rojas L, Rangel R, Guret C, Madrid-Marina V, et al. Regulation of CD40 and CD40 ligand by the AT-hook transcription factor AKNA. Nature. 2001:410:383-7.

21. Manzo-Merino J, Lagunas-Martínez A, Contreras-Ochoa CO, Lizano M, Castro-Muñoz LJ, Calderón-Corona C, et al. The human papillomavirus (HPV) E6 oncoprotein regulates CD40 expression via the AT-hook transcription factor AKNA. Cancers (Basel). 2018;10:10120521.

22. Hibma $\mathrm{MH}$. The immune response to papillomavirus during infection persistence and regression. Open Virol J. 2012;6:241-8.

23. Moretta L, Bottino C, Pende D, Castriconi R, Mingari MC, Moretta A. Surface NK receptors and their ligands on tumor cells. Semin Immunol. 2006;18:151-8.

24. Garcia-Iglesias T, Del Toro-Arreola A, Albarran-Somoza B, Del Toro-Arreola S, Sanchez-Hernandez PE, Ramirez-Dueñas MG, et al. Low NKp30, NKp46 and NKG2D expression and reduced cytotoxic activity on NK cells in cervical cancer and precursor lesions. BMC Cancer. 2009;9:186.

25. Edwards RP, Kuykendall K, Crowley-Nowick P, Partridge EE, Shingleton HM, Mestecky J. T lymphocytes infiltrating advanced grades of cervical neoplasia. CD8-positive cells are recruited to invasion. Cancer. 1995;76:1411-5.

26. Origoni M, Parma M, Dell'Antonio G, Gelardi C, Stefani C, Salvatore $S$, et al. Prognostic significance of immunohistochemical phenotypes in patients treated for high-grade cervical intraepithelial neoplasia. Biomed Res Int. 2013;2013:831907.

27. Díaz-Benítez CE, Navarro-Fuentes KR, Flores-Sosa JA, JuárezDíaz J, Uribe-Salas FJ, Román-Basaure E, et al. CD3zeta expression and T cell proliferation are inhibited by TGF-betal and IL-10 in cervical cancer patients. J Clin Immunol. 2009;29:532-44.

28. Pardoll DM. The blockade of immune checkpoints in cancer immunotherapy. Nat Rev Cancer. 2012;12:252-64.

29. Nirschl CJ, Drake CG. Molecular pathways: coexpression of immune checkpoint molecules: signaling pathways and implications for cancer immunotherapy. Clin Cancer Res. 2013;19:4917-24.

30. Ohaegbulam KC, Assal A, Lazar-Molnar E, Yao Y, Zang X. Human cancer immunotherapy with antibodies to the PD-1 and PD-L1 pathway. Trends Mol Med. 2015;21:24-33.

31. Parry RV, Chemnitz JM, Frauwirth KA, Lanfranco AR, Braunstein I, Kobayashi SV, et al. CTLA-4 and PD-1 receptors inhibit T-cell activation by distinct mechanisms. Mol Cell Biol. 2005;25:9543-53.

32. Kosmaczewska A, Bocko D, Ciszak L, Wlodarska-Polinska I, Kornafel J, Szteblich A, et al. Dysregulated expression of both the costimulatory CD28 and inhibitory CTLA-4 molecules in PB T cells of advanced cervical cancer patients suggests systemic immunosuppression related to disease progression. Pathol Oncol Res. 2012;18:479-89.

33. Lheureux S, Butler MO, Clarke B, Cristea MC Martin LP, Tonkin $\mathrm{K}$, et al. Association of ipilimumab with safety and antitumor activity in women with metastatic or recurrent human papillomavirus-related cervical carcinoma. JAMA Oncol. 2018:4:e173776.

34. Hodi FS, O'Day SJ, McDermott DF, Weber RW, Sosman JA, Haanen JB, et al. Improved survival with ipilimumab in patients with metastatic melanoma. N Engl J Med. 2010;363:711-23.

35. Liu C, Lu J, Tian H, Du W, Zhao L, Feng J, et al. Increased expression of PD L1 by the human papillomavirus 16 E7 oncoprotein inhibits anticancer immunity. Mol Med Rep. 2017;15:1063-70.

36. Saglam O, Conejo-Garcia J. PD-1/PD-L1 immune checkpoint inhibitors in advanced cervical cancer. Integr Cancer Sci Ther. 2018;5:1000272.

37. Reddy OL, Shintaku PI, Moatamed NA. Programmed death-ligand 1 (PD-L1) is expressed in a significant number of the uterine cervical carcinomas. Diagn Pathol. 2017;12:45

38. Heeren AM, Punt S, Bleeker MC, Gaarenstroom KN, van der Velden J, Kenter GG, et al. Prognostic effect of different PD-L1 
expression patterns in squamous cell carcinoma and adenocarcinoma of the cervix. Mod Pathol. 2016;29:753-63.

39. Mezache L, Paniccia B, Nyinawabera A, Nuovo GJ. Enhanced expression of PD L1 in cervical intraepithelial neoplasia and cervical cancers. Mod Pathol. 2015;28:1594-602.

40. Rizzo R, Gentili V, Rotola A, Bortolotti D, Cassai E, Di Luca D. Implication of HLA-C and KIR alleles in human papillomavirus infection and associated cervical lesions. Viral Immunol. 2014;27:468-70.

41. Ryu KS, Lee YS, Kim BK, Park YG, Kim YW, Hur SY, et al. Alterations of HLA class I and II antigen expression in preinvasive, invasive and metastatic cervical cancers. Exp Mol Med. 2001;33:136-44.

42. Rodríguez-Sastre MA, González-Maya L, Delgado R, Lizano M, Tsubaki G, Mohar A, et al. Abnormal distribution of E-cadherin and beta-catenin in different histologic types of cancer of the uterine cervix. Gynecol Oncol. 2005;97:330-6.

43. Aguilar-Lemarroy A, Romero-Ramos JE, Olimon-Andalon V, Hernandez-Flores G, Lerma-Diaz JM, Ortiz-Lazareno PC, et al. Apoptosis induction in Jurkat cells and SCD95 levels in women's sera are related with the risk of developing cervical cancer. BMC Cancer. 2008;8:99

44. López-Muñoz H, Escobar-Sánchez ML, López-Marure R, Lascurain-Ledesma R, Zenteno E, Hernández-Vazquez JM, et al. Cervical cancer cells induce apoptosis in TCD4+ lymphocytes through the secretion of TGF- $\beta$. Arch Gynecol Obstet. 2013:287:755-63.

45. Wu MY, Kuo TY, Ho HN. Tumor-infiltrating lymphocytes contain a higher proportion of FOXP3(+) T lymphocytes in cervical cancer. J Formos Med Assoc. 2011;110:580-6.
46. Heeren AM, Koster BD, Samuels S, Ferns DM, Chondronasiou $D$, Kenter GG, et al. High and interrelated rates of PD$\mathrm{L} 1+\mathrm{CD} 14+$ antigen-presenting cells and regulatory $\mathrm{T}$ cells mark the microenvironment of metastatic lymph nodes from patients with cervical cancer. Cancer Immunol Res. 2015;3: 48-58.

47. Escarra-Senmarti M, Bueno-Topete MR, Jave-Suarez LF, GomezBañuelos E, Gutierrez-Franco J, Vega-Magaña N, et al. Loss of CD28 within CD4+ T cell subsets from cervical cancer patients is accompanied by the acquisition of intracellular perforin, and is further enhanced by NKG2D expression. Immunol Lett 2017;182:30-8

48. Meng $Y$, Liang $H, H u$ J, Liu S, Hao X, Wong MS, et al. PD-L1 expression correlates with tumor infiltrating lymphocytes and response to neoadjuvant chemotherapy in cervical cancer. ] Cancer. 2018;9:2938-45.

49. Wang Y, Li G. PD-1/PD-L1 blockade in cervical cancer: current studies and perspectives. Front Med. 2019;13:438-50.

50. Kang J, Demaria S, Formenti S. Current clinical trials testing the combination of immunotherapy with radiotherapy. J Immunother Cancer 2016;4:51.

51. Borcoman E, Le Tourneau C. Pembrolizumab in cervical cancer: latest evidence and clinical usefulness. Ther Adv Med Oncol. 2017;9:431-9

52. Liu $Y, W u L$, Tong $R$, Yang $F$, Yin $L$, Li $M$, et al PD-1/PD-L1 inhibitors in cervical cancer. Front Pharmacol. 2019;10:65.

53. De Felice F, Marchetti C, Palaia I, Ostuni R, Muzii L, Tombolini V, et al. Immune check-point in cervical cancer. Crit Rev Oncol Hematol. 2018;129:40-3. 